\title{
A Modest Defense of Manifestationalism
}

\author{
Jamin Asay \\ University of Hong Kong \\ S. Seth Bordner \\ The University of Alabama
}

\begin{abstract}
:
As the debate between realists and empiricists in the philosophy of science drags on, one point of consensus has emerged: no one wants to be a manifestationalist. The manifestationalist is a kind of radical empiricist who argues that science provides theories that aim neither at a true picture of the entire world, nor even an empirically adequate picture that captures the world in all its observable respects. For manifestationalists, science aims only at providing theories that are true to the observed aspects of reality. If the guiding idea of empiricism is that experience, and experience alone, provides us with knowledge about the world, then manifestationalism is an exceptionally strict empiricist perspective on science.

Manifestationalism has primarily served within a reductio: certain empiricist views and arguments, when taken to their logical conclusion, lead to manifestationalism and so cannot be correct. The reductio works only because manifestationalism is widely agreed to be a nonstarter. However, this consensus against manifestationalism is based on a single argument. We contest this assessment of manifestationalism and show that the primary argument against manifestationalism fails to hit its target. We do not intend to offer a manifesto for manifestationalism. Rather, we aim to vindicate it from a false accusation. Manifestationalism may not be the correct view of science, but the objections levied against it so far can be met.
\end{abstract}

Keywords: manifestationalism; empiricism; realism; Bas van Fraassen; Gideon Rosen

\section{Introduction}

As the debate between realists and empiricists in the philosophy of science drags on, one point of consensus has emerged: no one wants to be a manifestationalist. The manifestationalist is a kind of radical empiricist who argues that science provides theories that aim neither at a true picture of the entire world, nor even an empirically adequate picture that captures the world in all its observable respects. For manifestationalists, science aims only at providing theories that are true to 
the observed aspects of reality. If the guiding idea of empiricism is that experience, and experience alone, provides us with knowledge about the world, then manifestationalism is an exceptionally strict empiricist perspective on science.

Manifestationalism in the philosophy of science has surfaced primarily to serve within a reductio: certain empiricist views and arguments, when taken to their logical conclusion, lead to manifestationalism and so cannot be correct. The reductio is thought to work because manifestationalism is widely agreed to be a non-starter. As we shall see, this consensus is founded upon the basis of just one argument. We contest this assessment of manifestationalism, and our aim in this paper is to show that the primary argument against manifestationalism fails to hit its target. We do not intend to offer a manifesto for manifestationalism; rather, our attempt is to vindicate it from a false accusation. Thus, even if manifestationalism is not the correct view of science, the objections levied against it so far can be met. If we ought not to accept manifestationalism as a viable philosophy of science, we will need further, more convincing reasons.

Our modest defense of manifestationalism plays a broader dialectical role as well. By disregarding the manifestationalist position (and the strict empiricism it endorses), the dialectic in the philosophy of science shifts to the benefit of realists. All sides concede that no position stricter than constructive empiricism is tenable. But the arguments for various modest forms of empiricism are frequently thought to lead to manifestationalism. So the distrust of manifestationalism bleeds into a broader questioning of all empiricist positions. By meeting the standing objection to manifestationalism in particular, we thereby defend a more general empiricist perspective, and remove one weapon from the realist's arsenal.

We begin by offering what we take to be the most accurate statement of manifestationalism and examine what role it plays in the dialectic between realists and empiricists. From this we reconstruct the "master argument" against empiricism, which begins by establishing that if one is an 
empiricist, then one should be a manifestationalist. This conditional is then paired with a supposed refutation of manifestationalism, resulting in a modus tollens against empiricism. We confront this attempted refutation, and show that it is unsuccessful. To conclude, we consider the heretofore unnoticed merits of manifestationalism, though we remain agnostic as to whether those merits are sufficient to overcome the competition.

\section{Manifestationalism Defined}

Given that manifestationalism (M) plays directly into the dialectic between constructive empiricists and realists, we define it exactly parallel to how Bas van Fraassen (1980: 8, 12) defines scientific realism (SR) and constructive empiricism (CE):

(SR) Science aims to give us theories that are literally true; acceptance of a theory involves the belief that it is literally true.

(CE) Science aims to give us theories that are empirically adequate; acceptance of a theory involves only the belief that it is empirically adequate.

These definitions, while familiar, require some elaboration. A true theory, for van Fraassen's purposes, is one that not only speaks only truths, but also speaks all truths. Similarly, an empirically adequate theory is one that captures all the phenomena. So scientific theories haven't met their aim until they are comprehensive (van Fraassen 1980: 64 and 1989: 226). Acceptance also involves a pragmatic aspect: to accept a theory is to immerse yourself in its worldview for purposes of offering explanations, writing grants, etc. (van Fraassen 1980: 12). There are further questions, such as the nature of scientific theories and the nature of the observable/unobservable distinction in terms of which empirical adequacy is defined, but these are unimportant for present purposes. 
Whereas CE is defined in terms of empirical adequacy, where empirical adequacy is weaker than truth, we define $\mathrm{M}$ in terms of a notion still weaker, which we'll call manifest adequacy. Theories are manifestly adequate when they correctly capture not all phenomena, but only the observed phenomena. Of course, the list of observed phenomena is constantly growing, as we make more and more observations. Critics of manifestationalism have seemed to treat manifest adequacy in its weakest formulation, namely, that a theory is manifestly adequate just in case it is true to all of the phenomena observed so far. We intend an exhaustive notion of the observed phenomena-every phenomenon that ever has been or will be observed — and thus a comprehensive notion of manifest adequacy. ${ }^{1}$ A comprehensively manifestly adequate theory is one which captures all truths about all the observed phenomena, whether past, present, or future. Even still, the list of observed phenomena will be miniscule compared to the list of observable phenomena as CE understands the term. Many observable phenomena will never be observed. This allows us to define M exactly parallel to SR and CE:

(M) Science aims to give us theories that are comprehensively manifestly adequate; acceptance of a theory involves only the belief that it is comprehensively manifestly adequate.

A few provisos: $\mathrm{M}$ is a theory about science, not about the aims or motivations of actual individual scientists, or even an abstracted ideal scientist (van Fraassen 1994 and Psillos 1999: 192-

\footnotetext{
${ }^{1}$ Note, as will be important later, that observed phenomena are not limited solely to those observations that scientists make when they are intentionally pursuing their scientific aims. All observed phenomena-regardless of whether or not they are observed "on the clock" — are relevant to science, as realists, constructive empiricists, and manifestationalists can all agree.
} 
193). Scientists may engage in science for any number of reasons and have any number of aims, none of which need be the aim of science itself. Science is to be understood as a collective ongoing enterprise, pursued by a large community of individuals whose interests spread across different disciplines, and whose work continues across a large breadth of space and time. Hence, $\mathrm{M}$ is not a view about the aim of science considered from a moment in history, no more than are SR and CE. The aim of science is to be thought of from a long view about what science aims to have accomplished when it is completed. Suppose that scientific inquiry continues right up to the heat death of the universe. How might we describe the aim of science, looking back at its history from its conclusion? Considered this way, the manifestationalist holds that the aim of science is — and always has been — to produce theories that are true of all the phenomena that end up being observed, and that accepting a theory requires only — and has always required only — believing that a theory is true of all those observed phenomena. The manifestationalist holds that believing further in the truth or empirical adequacy of a theory with respect to the unobservable or the merely unobserved is (and always has been) supererogatory. ${ }^{2}$ Notice, finally, that M, like SR and CE, is a

\footnotetext{
${ }^{2}$ It may seem that the difference between $\mathrm{M}$ and $\mathrm{CE}$ boils down to a disagreement about what things count as observable. But this is not right; rather, the difference concerns the scientific-epistemic relevance of the (shared) conception of the observable. On CE, observability is epistemically important because it corresponds to (some of) the limits of human experience. Since (so far) only humans engage in scientific inquiry, what is observable to them is relevant to science, and what is not, is not (even if much of what there is is unobservable). For M, the concept of observability is no less intelligible, it is simply less epistemically salient for the purposes of science. One way to put it is to say that (for M) since scientific inquiry only directly discloses information about the observed, what is observed is relevant to science, and what is not, is not (even if much of what is not observed is still, in some sense, observable). A second, deeper concern might be that $\mathrm{M}$ threatens to collapse into a phenomenalism or even solipsism of the present moment: if only what is observed is relevant to scientific inquiry, then perhaps only what is observed-immediately-hereand-now-by-me will escape certain skeptical worries. This is a concern, but not one unique to M. The slide to solipsism
} 
philosophical thesis, a claim about the nature of scientific inquiry. One can be a manifestationalist and still believe in the empirical adequacy or even truth of some scientific theory; it's just that in so doing, one is going beyond what science minimally requires (cf. van Fraassen 1994: 182).

\section{Manifestationalism Deployed}

No one, to our knowledge, has ever endorsed manifestationalism. Peter Railton (1989: 231248) coined the term, and it has since been deployed in various discussions of and arguments against constructive empiricism (Rosen 1994: 161-163, Alspector-Kelly 2001 and 2006, Monton and van Fraassen 2003: 407-408, Ladyman 2004: 757-758 and 2007: 48-49, Cartwright 2007, and Ladyman and Ross 2007: 103-110). ${ }^{3}$ The standard argumentative strategy is to show that the considerations

is, of course, a familiar thought of where empiricism ends up in the limit. And so we are cautious not to claim, as does van Fraassen on behalf of $\mathrm{CE}$, that $\mathrm{M}$ is somehow the principled stopping point between full-blown realism and extreme skepticism. Whether $\mathrm{M}$ is ultimately stable in the face of extreme skeptical challenges goes beyond the scope of this paper. After all, ours is a modest defense of $\mathrm{M}$ against the only outstanding challenge raised against it, a challenge that has been convincing enough to preempt further discussion of the view until now. So, if we are right that the extant objection to $\mathrm{M}$ fails, we have no reason (so far) to think that $\mathrm{M}$ is any less principled or stable a view than CE or any other empiricist view, which are each fundamentally non-skeptical about the external world. No doubt, M by itself does not address extreme external world skepticism, but then neither does CE by itself. M, like CE, is a view about the aim of science that brackets deeper skeptical concerns out of dialectical necessity.

${ }^{3}$ It is worth noting that Railton's initial formulation is importantly different than ours. Railton defines manifestationalism by first describing a manifest theory, "which says all that the observational theory says about observed observables — past, present, or future—but which is altogether silent about unobserved observables” (1989: 235). Presumably, a manifestationalist for Railton is one who accepts only the manifest theory. On Railton's definition, the manifestationalist accepts a different theory than does the constructive empiricist and the realist. But this is not how we understand manifestationalism. Manifestationalism, like CE and SR, is a view about what science aims to do and what one's epistemic obligations are in order to do science. Manifestationalists may accept the very same theories as scientific 
that favor CE, when taken to the limit, actually turn out to favor M. Furthermore, any attempt to stop the slide from CE to M can be turned against the empiricist, thereby providing a path from CE back to SR. This dialectic presumes that M is untenable, and thereby purports to show that CE is not, contra van Fraassen, a stable empiricist resting point between realism and the extreme empiricism represented by $\mathrm{M}$.

The argument begins by clarifying what exactly the constructive empiricist is attempting to accomplish: a rational reconstruction of scientific inquiry that respects both (i) actual scientific practice and (ii) a broadly empiricist epistemology. Van Fraassen expresses the spirit of empiricist epistemology as a desire to limit belief to what can at least in principle be disclosed in experience (van Fraassen 1985: 258). The reasons are simple: science is a distinctly human enterprise, human beings are subject to natural limitations on the kind of things that they can observe, and so the limits of human observation mark an important limit of the relationship between scientific theory and our experience. Of course, scientific theories have implications and postulate entities outside the observable realm. That is no matter for CE and its epistemology, however, since CE maintains that since the theories can only be tested against their observable consequences, one may remain agnostic with respect to the parts of those theories that speak to unobservable entities. According to CE, one can accept the theory that there are electrons insofar as one believes that the observable phenomena are as the theory says they are, even if one refuses to believe that there are electrons after all.

In their reconstruction of scientific inquiry, then, empiricists interpret the aim of science in a way that respects the limits of our sensory faculties. And while it is not irrational to extend one's beliefs beyond what is observable, doing so is not required by scientific practice, and van Fraassen has harsh words for those who do take such unnecessary cognitive leaps:

realists, though accepting a theory, for a manifestationalist, means something different than for a realist. 
If I believe the theory to be true and not just empirically adequate, my risk of being shown wrong is exactly the risk that the weaker, entailed belief will conflict with actual experience. Meanwhile, by avowing the stronger belief, I place myself in the position of being able to answer more questions, of having a richer, fuller picture of the world, a wealth of opinion so to say, that I can dole out to those who wonder. But, since the extra opinion is not additionally vulnerable [to disconfirmation through observation], the risk is - in human terms-illusory, and therefore so is the wealth. It is but empty strutting and posturing, this display of courage not under fire and avowal of additional resources that cannot feel the pinch of misfortune any earlier. What can I do except express disdain for this appearance of greater courage in embracing additional beliefs which will ex bypothesi never brave a more serious test? (1985: 255)

Here van Fraassen argues that there is nothing to be gained scientifically in extending one's beliefs into the realm of the unobservable. A theory's being true entails that it is empirically adequate, but not vice versa. Since there is no possible evidence for the former that isn't also evidence for the latter, there is no possible evidence that could ever tell between empirically identical theories. Those who choose nevertheless to believe in the truth of some theory take on an extra commitment that could never be challenged or supported any more than the belief that the theory is merely empirically adequate.

The problem for constructive empiricism is that the passage just quoted can immediately be turned against constructive empiricism in favor of M. Simply replace 'true' with 'empirically adequate' and 'empirically adequate' with 'comprehensively manifestly adequate' and we have an exactly parallel argument that any belief in unobserved observables is just as extraneous and supererogatory as any belief in unobservables. By definition, the only phenomena that could serve to 
distinguish between competing manifestly adequate theories are ones that will never be observed. The very empiricist argument used to motivate $\mathrm{CE}$ is, it turns out, better suited to motivate M.

We may now reconstruct the "master argument" against empiricism by way of M: ${ }^{4}$

(1) If one is an empiricist, then one should understand the aim of science in a way that (i) respects empiricist epistemology and (ii) makes sense of actual scientific practice.

(2) Empiricist epistemology maintains that experience is the sole legitimate source of information about the world, and so an empiricist has no epistemic obligations to hold beliefs that go beyond the boundaries of experience.

(3) CE, but not M, maintains that the aim of science extends beyond the limit of the evidence available to the members of the community of observers (given their sensory faculties) and thus requires beliefs that go beyond the boundaries of experience (past, present, and future).

The argument's first two premises are presumably accepted by all parties to the debate, or at least all who accept van Fraassen's construal of realism and empiricism. The third premise is similarly uncontroversial, and is especially urged by those (notably Railton and Alspector-Kelly) who see constructive empiricism as an unprincipled compromise between realism and empiricism. And so we might be inclined to conclude that if one is an empiricist, then one should accept M, not CE.

However, the argument here takes a turn against $\mathrm{M}$. The correct account of the aim of science needs not only to be epistemologically sound, but also able to make sense of the practice of actual science. And it is frequently claimed that M, unlike CE, cannot account for some crucial

\footnotetext{
${ }^{4}$ Note that the argument, given the focus of our paper, assumes that constructive empiricism and manifestationalism are the only empiricist contenders.
} 
aspects of scientific inquiry (see especially Rosen 1994 and Monton and van Fraassen 2003). The basic objection is that $\mathrm{M}$ cannot explain the scientific thirst for generating new observations, i.e., for turning unobserved phenomena into observed phenomena. (We evaluate this objection in full in the next section.)

Hence, while M might better realize empiricist epistemology, it cannot, say its detractors, make sense of actual scientific practice. At this point, opinions diverge. The constructive empiricist claims victory: though $\mathrm{M}$ may better realize empiricist epistemological virtues, $\mathrm{CE}$ remains the empiricist package that best captures both empiricist desiderata (Monton and van Fraassen 2003: 407). The realist (see, e.g., Psillos 1999), noticing the tension between the two desiderata, concludes: so much the worse for empiricism. Empiricist scruples lead to an unsteady view, and so CE is not a principled stopping ground against manifestationalist worries. Since even constructive empiricists are required to hold beliefs that go beyond the immediate deliverances of experience, they are in no position to criticize the realist for doing the same. One should just accept SR and be done with it. To complete the master argument we need the fourth premise:

(4) M cannot make sense of actual scientific practice.

This premise spells doom for M. Constructive empiricists go on to settle the argument in their favor:

(5) CE can make sense of actual scientific practice.

(6) So, CE is better at respecting empiricist epistemology and making sense of actual scientific practice than $\mathrm{M}$.

(7) So, if one is an empiricist, one should accept CE. 
The realist, by contrast, goes a different direction:

$\left(5^{*}\right) \quad$ No empiricist philosophy of science both respects empiricist epistemology and makes sense of actual scientific practice.

(6*) So, one should not be an empiricist.

We reject both perspectives on the argument, given that we dispute the supposed refutation of $\mathrm{M}$ that lies behind premise (4), to which we now turn.

\section{Manifestationalism Defamed}

The main objection to M, due initially to Gideon Rosen, is that it cannot make sense of the obvious scientific practice of seeking out new phenomena. He provides the following thought experiment to demonstrate:

Consider, for example, an archeologist whose theory covers all the evidence so far collected about Etruscan urns. He has sole license to dig in the last uninspected patch of ground, but it is also in his power to destroy the site so that no one will ever have a chance to inspect it. What should he do? A real scientist would dig, of course. And this is just what we should expect if his aim were to produce empirically adequate theories in van Fraassen's sense. For then he would regard his theory as responsible to the urns that are now still undergroundbecause they are observable things— whether or not anyone actually observes them. But what sense can the manifestationalist make of this digging? From where he sits, the archeologist who digs risks turning an adequate theory into an inadequate one by unearthing the sole extant counterexample. On the other hand, by destroying the site he will have guaranteed that 
his theory is ideal by his lights, i.e., adequate to the actually observed phenomena in its intended domain. Manifestationalism therefore motivates an ostrich-like ducking at crucial moments which is clearly incompatible with the imperative to observe as much as possible that informs all real science. Actual science does not proceed as if manifestationalism were a true account of the aims and attitudes of scientists. A theorist who adopts it must therefore regard much of what scientists do as irrational given his conception of the aim of the practice; and to this extent he must either seek to reform it or to opt out. (1994: 162) ${ }^{5}$

Rosen's argument is that M does not make sense of science because those who align themselves with what M says is the aim of science thereby commit themselves to not creating new observed phenomena. Furthermore, Rosen claims that $\mathrm{M}$ entails that it is irrational to make new observations if one's current theories are so-far manifestly adequate. Real scientists seek out new phenomena, and this is a salient fact about the aim of science that $\mathrm{M}$, allegedly, not only fails to predict, but claims to be irrational.

We reconstruct Rosen's argument as follows:

(R1) In the example, the archaeologist has a theory that is true to all the phenomena observed so far; as a result, her theory is, as of now, manifestly adequate and so satisfies the aim of science (according to M).

\footnotetext{
${ }^{5}$ Cf. Railton 1989: 240-245. Monton and van Fraassen concur with Rosen’s analysis (2003: 407). Alspector-Kelly grants that while the example makes trouble for M, it still pushes empiricists away from CE and closer to M (2001: 416-417, note 3 and 2006: 372-374). Ladyman attempts to turn Rosen's style of argument against CE, providing a case where it is the constructive empiricists supposedly sticking their heads in the sand (2000: 852-853; see also Rosen 1994: 177-178, endnote 13 and Ladyman and Ross 2007: 109-110). We believe that this anti-CE argument fails for precisely the same reasons as Rosen's, as we explore below.
} 
(R2) If she digs at location $L$, it is possible that she will observe facts that conflict with her theory.

(R3) So, if she digs at $L$, she risks the manifest adequacy of her theory and risks her undoing her successful achievement of the aim of science (according to $\mathrm{M}$ ).

(R4) If she blows up the site, she will ensure the manifest adequacy of her theory.

(R5) So, if she accepts M, it would be irrational for her to dig at L; she should blow up the site.

Since R5 is so at odds with the most basic practices of science, M cannot be correct in its identification of the aim of science.

We agree that if $\mathrm{M}$ entails $\mathrm{R} 5$, then $\mathrm{M}$ fails to account for scientific practice. However, there are (at least) five problems with Rosen's argument, any one of which vitiates its conclusion. We conclude that $\mathrm{M}$ does not entail R5.

First, R1 is an inaccurate description of the situation. A theory that is adequate only to the phenomena observed so far is not comprehensively manifestly adequate, since comprehensive manifest adequacy requires adequacy to all the observed phenomena, including those that will be observed (but not phenomena that might have been observed but weren't). So, according to M, the aim of science has not already been fulfilled by the archaeologist's theory since, so long as human beings continue to survive, there will continue to be new observations for theories to account for. As a result, there is no "risk" of turning a manifestly adequate theory into an inadequate one, since the archaeologist does not start with a manifestly adequate theory.

Second, the archaeologist is never in a position to know that her theory is manifestly adequate (comprehensively so or otherwise), even if it were. But such knowledge is required if the archaeologist is to be in a position to engage in the sort of normative reasoning that Rosen offers 
her on behalf of $\mathrm{M}$. If there are urns heretofore unknown to archaeologists at $L$, then those urns were created by human hands, and so are a source of many already observed phenomena from the past that the archaeologist's theory does not currently account for. Since her theory does not already presuppose the existence of such urns nor, if the archaeologist knew her theory was already so-far manifestly adequate, she would know that there are no urns at $L$. But, ex bypothesi, she does not know that there are no urns there. So she doesn't know whether or not her theory is even so-far manifestly adequate. The bottom line is that if we want to derive a conclusion about what $\mathrm{M}$ tells the archaeologist she should or shouldn't do, we have to start not with R1, but the stronger claim that the archaeologist knows that R1 is true. But even if R1 were true (which it's not), the archaeologist would not be in a position to know that.

Third, while it is true that the archaeologist risks the potential comprehensive manifest adequacy of her current theory by digging, it is false that she avoids the risk by blowing up the site, as R4 suggests. The choice for the archaeologist is not whether to have observations or not, but whether to have these observations or those. Passing on some observations creates opportunities for others to occur. The ostrich whose head is in the sand is still observing features of the world that the other ostriches nearby are missing. The archaeologist who chooses not to dig does not make an observation regarding the presence of urns in $L$ but she does make other observations that her theory, or other theories, will have to account for. There simply is no way-short of every last one of us committing mass, coordinated suicide_ of not creating new observed phenomena. The only way to avoid bringing about new observed phenomena (and thus end the need for science, according to manifestationalists) is to cease having experiences altogether. On the minimal assumption that we survive as a species, plenty more phenomena will be observed. Manifestationalism requires that scientific theories account for those observations, whatever they turn out to be. But, importantly, there is no way to know in advance or ensure that the phenomena 
that will be observed will or won't threaten theories that are so-far adequate to the observed phenomena (provided, of course, that one is not in a position to immediately initiate the apocalypse). R4 is false.

Fourth, Rosen's argument is improperly framed around the goal of preserving the manifest adequacy of the archaeologist's current theory. Rosen argues that because the adequacy of the theory is at risk, the archaeologist is motivated to do whatever is necessary to preserve the theory's adequacy. But Rosen's focus is on the wrong element of the case. The archaeologist, as a scientist, is concerned with ending up with a manifestly adequate theory, whatever that theory might be. M does not encourage the archaeologist not to dig for that last Etruscan urn because M does not hold that the aim of science is to preserve the adequacy of the theories we already hold. It maintains, rather, that whatever choice the archaeologist makes, and whatever observations are in fact made, it will be her task to produce and accept theories that account for all the phenomena she and others observe. If she chooses to dig, then she can easily continue to hold a so-far manifestly adequate theory, even if it's a different theory than the one she held before the dig. With new evidence in hand about whether or not there are urns at $L$, she can immediately accept a theory that continues to be so-far manifestly adequate, supposing she started out with one. Should this involve a change in which theory she accepts, that is no worry for the manifestationalist. Science does not operate with an injunction to preserve one's present theories, come what may. The manifestationalist claims instead that one should aim at theories that are manifestly adequate, whichever ones they may be. At worst, the choice to dig will result in the archaeologist's present theory no longer being so-far manifestly adequate. But in no way will it compromise what really matters: the archaeologist's being in a position to accept a comprehensively manifestly adequate theory, and thereby achieve the aim of science. If she chooses not to dig, her theory will continue to be manifestly adequate with respect to the urns, though she will open herself up to different adequacy worries concerning all sorts of other matters (such as 
psychological theories about the effects on archaeologists from destroying their own archaeological sites).

Our fifth and final objection is the most substantial. Rosen's view, in effect, is that M entails that we should do everything in our power to reduce the number of observations, so as to minimize the chance of science not reaching its aim. (Rosen even goes so far as to infer that not minimizing risk in this way is somehow irrational, according to M.) Only if one accepts something like this can one conclude R5 from R1-R4. As already discussed, it's not even clear that it's possible to ease the burden on manifest adequacy by "minimizing observations": the choice not to produce an observation of one kind is a choice to produce an observation of another kind. Science is interested in accounting for the observed phenomena, regardless of what they turn out to be. Even setting this aside, it's still unclear why this normative claim about what scientists should or shouldn't do automatically follows from a claim about the aim of science.

We staunchly deny that any such normative claim is entailed by M. And we argue further that neither CE nor SR entail any such normative claims. Thinking in terms of the "aim" of science can easily mislead. 'Aim' is ambiguous between "goal" or "end product" on the one hand, and the intention to achieve a goal on the other. Science as a practice has a goal-aim — the production of theories of a certain sort — much like chess has a goal-aim: the checkmate of one's opponent. As van Fraassen notes, however, the aim of a practice determines what counts as success in the practice, but this aim may be pursued for any number of reasons (van Fraassen 1980: 8).

If we ask why a given scientist is engaged in a particular scientific practice (such as an archaeological dig), the answer cannot be simply because that is scientific practice and she is a scientist any more than the answer to why a physician gives a patient a certain drug is because that is medical practice and she is a doctor. Nor can the answer simply be because science aims at providing true (or empirically adequate, or comprehensively manifestly adequate) theories, any more than the answer to the question about the 
physician can simply be because medicine aims at a patient's health. It is our desire for these goods that ultimately explains why we do these things. Specifying the aim of science no more provides a motivating reason to engage in science than specifying the aim of stamp collecting provides a motivating reason to become a philatelist. Nor does supposing antecedently that one is a scientist answer the question of whether and how to conduct experiments any more than antecedently supposing one is a stamp collector answers the question of whether to continue collecting stamps, or which to collect.

So it cannot be the case that manifestationalism's conception of the aim of science entails that one should or should not engage in science. Nor does it entail anything about which sorts of scientific endeavors one should engage in. It says only that if one is engaged in science, one is engaged in a practice the minimal goal-aim of which is a comprehensively manifestly adequate theory. Whether the archaeologist should dig or not depends on whether she wants to know if there is an urn at $\mathrm{L}$, not on her role as a scientist or on her acceptance of $\mathrm{M}$ (or CE or SR) as the correct description of the aim of science. It is her desire to know that explains her being a scientist, not the other way round.

Recall that M differs from CE and SR only in terms of which phenomena it considers scientifically relevant and of what epistemic responsibilities are incurred when accepting a theory. If, then, observation-minimizing normative conclusions follow from $\mathrm{M}$ (which we deny) we see no reason why they would not follow from both CE and SR as well. But they do not follow from either $\mathrm{CE}$ or SR, even though Rosen-style cases can easily be constructed against both views. According to $\mathrm{CE}$, for instance, acceptance of a scientific theory involves the belief only that the theory is empirically adequate, where what counts as empirical adequacy is a function of the sensory limitations of the human community (van Fraassen 1980: 17). Those limitations, however, are contingent and malleable, even though their contigency and malleability are not as obvious as in the 
case of deciding which observations to make. What's more, van Fraassen admits that changes in our perceptual abilities would require us to revise our conception of the observable, and a fortiori, what counts as empirical adequacy. ${ }^{6}$

We could organize a selective breeding program to progressively diminish the perceptual abilities of human beings, changing our community of observers into a species of deaf and blind beings with no senses of taste or smell. If Rosen's objection leads to the conclusion that a manifestationalist should choose to forego additional experiments rather than risk the adequacy of her theory, then it likewise recommends to the constructive empiricist that we start selecting for insensibility. Or, since van Fraassen was considering the impact of the addition of more perceptive beings to our community of observers, we might at the very least avoid steps that make our meeting such beings more likely. After all, to fail to do so is to run the unnecessary risk of expanding (or failing to keep narrow) the range of observable phenomena against which our theories will be tested.

Or, supposing certain quantum phenomena are literally indeterminate until measured, it would follow from a similar understanding of SR that such measurements should not be done at all. To do so would be to create a new fact for which our theories must now account, one that would not be a fact at all if we chose the "safe" route of avoiding such messy, work-increasing experiments.

We conclude that M is saddled with the timid, "ostrich-like" imperative to minimize observations only if CE and SR are likewise challenged (which they are not). Rosen's concern about this imperative, recall, is that it conflicts with what he thinks are legitimate, bold imperatives belonging to science, namely, "to observe as much as possible" and "to produce as many new sorts of phenomena as possible" (1994: 162,178, note 13). But the aim of science should not be thought of as including these imperatives either, for similar reasons. Given these imperatives, CE

\footnotetext{
${ }^{6}$ Van Fraassen (1980: 18): "[T] he anti-realist would, on my proposal, have to accept conditions of the form: If the epistemic community changes in fashion $Y$, then my beliefs about the world will change in manner $Z$."
} 
recommends selective breeding to increase our sensory abilities, so as to increase the number of phenomena we may observe. Likewise, SR would recommend that we spend all of our resources to measure as many quantum phenomena as possible, so as to maximize the number of facts for which science is accountable. Furthermore, an imperative to produce as many new sorts of phenomena as possible would recommend, for example, never replicating past experiments. If we have a choice between confirming an already observed phenomenon or exploring a new one, Rosen would always have us choose the latter course. But of course this is all nonsense. The aim of science, by itself, does not issue these sorts of prescriptions.

In short, to commit to a view about the aim of science is not to commit to doing everything possible to avoid the risk of not satisfying that aim (supposing that's even a legitimate worry, which we have already doubted), nor is it to commit to observing as much as possible. Views like M, CE, and SR do not entail conclusions about which observations should or shouldn't be carried out. Decisions to carry out certain observations come with inevitable opportunity costs that preclude making other observations. Scientists are finite beings with limitations on the kinds and number of observations they can make. There can be no scientific injunction to collect all possible observations. The observations we do make — whether they involve looking for urns at L or not, or creating new kinds of phenomena instead of exploring old kinds of phenomena — are reflections of our particular thirsts for knowledge: what do we want to be included in our comprehensively manifestly adequate theories? We look for the urns if we want to know about the urns; we blow up the site if we want to know about the psychological effects on archaeologists of destroying their life's work. It is not the aim of science that directs us toward the observations we are to make; it is our personal aims that inform our observational choices. The aim of science informs us what our attitude should be toward scientific theories, given the way our personal aims have shaped the particular development of those theories. 
We conclude that the master argument's fourth premise is false, and that $\mathrm{M}$ has not been refuted. Properly understood, $\mathrm{M}$ does not have the absurd implications that others have claimed to find in it. This has implications for both SR and CE. It challenges SR insofar as it undermines one of the main arguments leveled by realists against $\mathrm{CE}$, namely the reductio that $\mathrm{CE}$ leads to $\mathrm{M}$, which is supposed to be absurd. It also provides a substantial challenge to current empiricists: given that empiricist arguments lead directly to $\mathrm{M}$ — a charge that can no longer be contested simply by claiming (falsely) that it cannot make sense of scientific practice — what is the rationale behind more permissive forms of empiricism like CE?

\section{Manifestationalism Defended}

Our aim, recall, is not to argue for the truth of M. Our first priority has instead been to defend it from unfair objections that have been lodged against it. That said, little has been said to advance the cause of the manifestationalist, and the view deserves a fair hearing. We conclude by considering a number of important (though not decisive) considerations in favor of the view. While we are unsure as to whether or not $\mathrm{M}$ offers the best rational reconstruction of scientific practice, we are convinced that those who coordinate their beliefs along manifestationalist lines are not thereby irrational. Our goal, then, runs parallel to van Fraassen's modest ambition for The Scientific Image, namely, to defend the rationality (but not necessarily the plausibility) of a particular empiricist perspective on science.

Perhaps the most likely reason that $\mathrm{M}$ has won over no advocates is that it can appear to present science as nothing more than a perpetually self-congratulating enterprise. Whatever collection of observations science has so far accumulated, M (supposedly) says that science aims at that, and so is constantly satisfying its aim, racking up victory after victory with every new observation. Properly understood, however, actual scientific practice has never satisfied the aim that 
$\mathrm{M}$ assigns to it. Manifest adequacy is not simply adequacy to the observed phenomena so far (a goal that already no scientific theory can claim to have achieved), but rather to all observed phenomena all told, whatever they turn out to be. Manifestationalism holds that science will have accomplished its aim when and only when we are in possession of theories that are true of all the actually observed phenomena, past, present, or future. This requirement is not some conveniently engineered addition to the manifestationalist platform to avoid the objections from Rosen and others, but a point of neutrality between M, CE, and SR. CE does not identify science's aim with saving the (observable) phenomena so far, nor does SR identify the aim of science with capturing the truth about reality up to now. Manifestationalists are done an injustice if they, and they alone, are saddled with the "so far" requirement.

Nor does M entail that it's irrational for people to believe anything that hasn't been observed. Similarly, CE does not entail that it is irrational for people to have beliefs concerning unobservable entities. Views about the aim of science are attempts to capture what counts as success in the scientific enterprise. They need not include the view that any belief above and beyond that aim is thereby irrational. Manifestationalism permits an individual's belief in the unobserved; it simply stresses that such belief is supererogatory from the perspective of science.

Some positive support for $\mathrm{M}$ comes from a familiar source, given our earlier study of the master argument. Many of the same considerations that motivate other empiricist positions like CE also motivate M. For example, both Railton (1989: 235-236) and van Fraassen (1985: 258) have defended CE as offering a principled restriction on the limits of belief, a restriction on what could be experienced. ${ }^{7}$ Unobservable entities are in principle beyond the scope of our senses, so it's no accident

\footnotetext{
${ }^{7}$ Here and elsewhere, we have employed apparently modal terminology about what is possible or impossible to observe. Van Fraassen and others have similarly described CE in early formulations, but the propriety of levying such modal assertions on behalf of CE has been challenged, most notably by Ladyman (2000 \& 2004). Ladyman's view is that in
} 
that we have no empirical evidence for them. But manifestationalists can offer principles of their own, and which better respect the epistemic modesty of empiricism. For example, it's no deep revelation that our possible observations are also limited by our species' particular location in space and time. We can have no physical contact with anything outside our species' light cone, and yet constructive empiricists maintain that science aims to capture the truth about the observable entities in those too-distant regions of the universe, even though it's impossible for us to make contact with them. Manifestationalists, by contrast, maintain that science can succeed in its aim even while remaining agnostic about such entities that are, in a very real sense, in principle impossible for us to observe.

Here is one final consideration in favor of $\mathrm{M}$. One might argue that the aim of an enterprise is closely related to, if not constituted by, what an ideal community of practitioners of that enterprise would accomplish under ideal circumstances. So imagine an ideal scientific community. This is a set of people like us, who share our sensory abilities and limitations, as well as our place and time in the universe. But they are always in "scientist mode," incessantly collecting and recording all of their observations. Regardless of what else they do in their scientific inquiries (and regardless of which phenomena they choose to investigate), they never miss recording an observation; all observed phenomena make it into their theories. Their data recording is exhaustive and never flawed, and the summation of their findings is, by definition, comprehensively manifestly adequate. The end product

espousing a philosophy of science that places considerable weight on the ostensibly modal 'observable,' the constructive empiricist is committed to modal realism. In response, Monton and van Fraassen (2003) have argued that, understood strictly, CE is neutral on the issue of modal realism since, surprisingly, 'observable' is not a modal term (Ibid., 411). Rather, claims about observability are facts disclosed by our best theories about the objects and the community of observers. Ultimately, the defender of manifestationalism is much less pressed to explain away modal claims since manifestationalism requires only that we can make sense of the concept of the observed. To the extent that what is observable goes beyond what is observed, manifestationalism is under no pressure to articulate the concept. 
of this ideal community's labors is guaranteed to be manifestly adequate, though not necessarily empirically adequate or true. Indeed, those latter features could never knowingly be achieved even by this ideal community of scientists, since even the totality of observed phenomena will leave underdetermined which of two or more manifestly adequate theories is empirically adequate, let alone true. Every observed fact will be captured by the theories they produce, and yet many morefacts about distant planets or the distant past, facts that both realists and constructive empiricists claim science aims to capture-will forever remain unaccounted for. And yet both the realist and the constructive empiricist hold that the ideal scientist onght to believe what the ideal theories say about such never-to-be-observed facts, beliefs which, ex hypothesi, will never brave any test at all. What a strange injunction! If the aim of an enterprise is something that is in principle attainable by the ideal practitioners of that enterprise under ideal circumstances, then only manifestationalism has a potential claim to having captured the aim of science. So perhaps manifestationalism has a fighting chance after all in the philosophy of science. ${ }^{8}$

\section{References}

Alspector-Kelly, Marc. 2001. Should the empiricist be a constructive empiricist? Philosophy of Science 68: 413-431.

- 2006. Constructive empiricism and epistemic modesty: response to van Fraassen and Monton. Erkenntnis 64: 371-379.

Cartwright, Nancy. 2007. Why be hanged for even a lamb? In Images of Empiricism: Essays on Science

\footnotetext{
${ }^{8}$ Earlier versions of this paper and related material were presented at the North Carolina Philosophical Society meeting and the Midsouth Philosophy Conference in 2011, and more recently to the Department of Philosophy at the University of Alabama. We'd like to thank the audiences at all of the above for helpful feedback. In addition, we owe special thanks to Marc Lange, Alan Nelson, John T. Roberts, and Chase Wrenn for reading and commenting on earlier drafts.
} 
and Stances, with a Reply from Bas C. van Fraassen, ed. Bradley Monton, 32-45. Oxford: Oxford University Press.

Ladyman, James. 2000. What's really wrong with constructive empiricism? Van Fraassen and the metaphysics of modality. British Journal for the Philosophy of Science 51: 837-856.

- 2004. Constructive empiricism and modal metaphysics: a reply to Monton and van Fraassen. British Journal for the Philosophy of Science 55: 755-765.

-. 2007. The epistemology of constructive empiricism. In Images of Empiricism: Essays on Science and Stances, with a Reply from Bas C. van Fraassen, ed. Bradley Monton, 46-61. Oxford: Oxford University Press.

Ladyman, James, and Don Ross (with David Spurrett and John Collier). 2007. Every Thing Must Go: Metaphysics Naturalized. Oxford: Oxford University Press.

Monton, Bradley, and Bas C. van Fraassen. 2003. Constructive empiricism and modal nominalism. British Journal for the Philosophy of Science 54: 405-422.

Psillos, Stathis. 1999. Scientific Realism: How Science Tracks Truth. London: Routledge.

Railton, Peter. 1989. Explanation and metaphysical controversy. In Minnesota Studies in the Philosophy of Science, Volume XIII: Scientific Explanation, eds. Philip Kitcher and Wesley C. Salmon, 220-252.

Rosen, Gideon. 1994. What is constructive empiricism? Philosophical Studies 74: 143-178.

van Fraassen, Bas C. 1980. The Scientific Image. Oxford: Clarendon Press.

—. 1985. Empiricism in the philosophy of science. In Images of Science: Essays on Realism and Empiricism, with a Reply from Bas C. van Fraassen, eds. Paul M. Churchland and Clifford A. Hooker, 245-308. Chicago: University of Chicago Press.

-. 1989. Laws and Symmetry. Oxford: Clarendon Press.

—. 1994. Gideon Rosen on constructive empiricism. Philosophical Studies 74: 179-192. 